\title{
Sobre a mulher em Contos de Kolimá*
}

Andrea Zeppini Menezes da Silva ${ }^{\star \star}$

Resumo: Este artigo propõe uma discussão a respeito das imagens femininas presentes em Contos de Kolimá, principal obra de Varlam Chalámov, que passou dezessete anos em campos do Gulag e escreveu sua prosa sobre essa experiência. Através de suas personagens femininas, 0 autor nos mostra importantes aspectos de sua visão de mundo, de sua ética, de sua prosa.

\begin{abstract}
This article proposes a discussion about the feminine images in Kolyma Tales, main work of Varlam Shalamov. He spent seventeen years in Gulag camps and wrote his prose about this experience. Through his female characters, the author shows us important aspects of his ethics and his prose.
\end{abstract}

Palavras-chave: Varlam Chalámov; Gulag; mulher Keywords: Varlam Shalamov; Gulag; woman 
* Artigo submetido em 04 de maio e aprovado em 03 de junho de 2018.

** Doutora pelo Programa de Literatura e Cultura Russa do Departamento de Letras Orientais da Faculdade de Filosofia, Letras e Ciências Humanas da Universidade de São Paulo. E-mail: dedazeppini@ hotmail.com

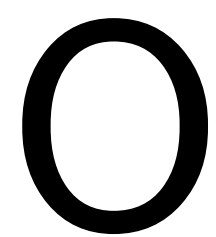

presente artigo se propõe a tratar de um tema na obra de Varlam Chalámov que, provavelmente por não ser central em sua prosa, ainda não foi muito explorado pela crítica: a questão do feminino.

Chalámov passou dezessete anos confinado nos piores campos do Gulag: a experiência é a base de sua escrita artística. $\mathrm{E}$ dezessete anos praticamente isolado das mulheres, com algumas exceções. É compreensível, portanto, que elas não ocupem um lugar de grande destaque em sua prosa. De todo modo, estão lá, ainda que em raras aparições. É justamente sobre algumas delas que comentaremos aqui, buscando uma reflexão sobre a imagem da mulher desenhada pelo autor nessas figuras. Como ele vê a mulher, como a apresenta em sua obra? No mundo de terror e violência vivido pelo autor, que papéis desempenham as mulheres, mais do que no campo, na escrita de seus contos? São essas as questões sobre as quais se debruça este artigo. Não há a intenção, portanto, de determinar neste trabalho a situação da mulher no Gulag de maneira geral. Trata-se apenas de verificar, através das personagens femininas escolhidas para este artigo, a visão de Chalámov sobre a mulher e o papeis desempenhados por ela em seus contos e em sua experiência no campo. Como já foi ressaltado, é um tema novo nos estudos sobre a obra do autor, o que não nos dá muito material prévio com o qual possamos dialogar.

Chalámov tem uma obra extensa: poesia, teatro, ensaios, cartas. Escolhemos aqui, para pensarmos o feminino em sua prosa, os Contos de Kolimá. Trata-se de sua obra-prima, composta por seis ciclos de contos onde o autor retrata, ficcionaliza e recria sua experiência nos campos stalinistas. Desses contos, selecionamos as personagens femininas que nos pareceram mais emblemáticas. 
Para iniciarmos, dois contos nos chamam a atenção. Já no primeiro volume, Contos de Kolimá, encontramos "Chuva" (1958) e "A primeira morte" (1956). Aparecem nessa ordem no ciclo - o que foi escrito antes vem depois - separados por alguns contos. "Chuva" trata de um dia de trabalho especialmente inóspito e terrível para os prisioneiros, obrigados a permanecerem horas a fio em poços que cavavam com pás e picaretas, enfiados na terra até a cintura, completamente encharcados durante vários dias, sob os açoites de uma chuvinha fininha e gelada. Enlouquecedor. A situação é tal que desperta no narrador suas lembranças sobre uma tentativa frustrada de suicídio - que ele não repetiria - e traz, a uma outra personagem, a decisão de se matar, que não se concretiza. Pois bem, é nesse contexto, no meio deste trabalho, que surge uma mulher:

Lembrei-me então da mulher que um dia antes passara por nós no atalho, sem dar atenção aos chamados da escolta. Nós a cumprimentamos e ela nos pareceu tão bonita: a primeira mulher que víamos em três anos. Ela acenou com a mão, apontou para o céu, para um ponto no canto do firmamento e gritou: "Está próximo, rapazes, está próximo". A resposta foi um berro animado. ${ }^{1}$

E é este simples gesto que vai marcar o narrador:

Nunca mais a vi, porém a vida inteira me lembrei dela: como conseguiu nos compreender e consolar daquele jeito. Apontou para o céu sem nem pensar no além-túmulo. Só indicou que o sol imperceptível se punha no ocidente, que estava próximo o fim do dia de trabalho. ${ }^{2}$

Não sabemos nada a seu respeito: o narrador diz tratar-se de uma prostituta ou ex-prostituta, pois, segundo ele, era só isso que as mulheres podiam fazer ali. Essa rápida menção à possível ocupação dessa personagem indica o lugar da mulher no contexto do trabalho escravo do campo. De todo modo, o narrador não dá mostras de conhecer a mulher nesse conto, mas nota que ela vem contrastar com o dia interminável, com o trabalho interminável, onde tudo, as montanhas, a chuva, o céu, as pessoas em suas roupas rotas, tudo, era cinzento, triste

1 CHALÁMOV, 2015, p. 58-59.

${ }^{2}$ Ibidem, p. 59. 
e construía uma "harmonia diabólica". É contra esse pano de fundo que surge essa mulher, encarnação, naquele momento, da esperança da única coisa boa que poderia acontecer: o término do dia de trabalho.

O próximo conto, "A primeira morte", trata justamente da morte da mulher que acenara para a brigada que trabalhava encharcada sob a chuva inclemente. Faz uma rápida menção a esse episódio para contar como a brigada encontrara seu corpo sem vida no meio da neve, em uma encruzilhada no caminho, ao lado de seu assassino, um agente de polícia especializado em produzir processos para os presos através de delações falsas, ameaças e subornos. Aqui, a mulher não é mais uma prostituta ou ex-prostituta, mas Anna Pávlovna, secretária do chefe da lavra. Era amada pela brigada, justamente por ter compreendido tudo o que um ser humano poderia compreender naquele momento do aceno, por ter infundido, com seu simples gesto, um pouco de confiança naqueles homens desesperados. A morte da mulher termina por expressar a injustiça e a extrema violência no campo. Não há lugar para a esperança e qualquer um, ou uma, que atente contra essa lei, recebe a morte como punição: Anna Pávlovna foi assassinada por ciúme.

O conto que vem imediatamente depois deste é "Tia Pólia" (1958), pertinente para nossa discussão, por trazer uma personagem feminina interessante. Tia Pólia era "faxina" do chefe da lavra. O que significa que era empregada da família e que, portanto, ocupava um cargo de confiança. Tão escrava quanto todos os outros detentos, com a diferença de que, ao invés de trabalhar nas minas, conseguira o cargo de cozinheira do chefe. Por estar tão próxima deste, como acontecia com outros "faxinas", Tia Pólia gozava de algum prestígio e o usava para ajudar seus conterrâneos ucranianos, arranjando-lhes serviços leves ou incluindo-os em alguma lista de soltura. Tia Pólia estava na casa do chefe há sete anos, mas ninguém ali sabia seu verdadeiro nome ou sobrenome. Ela contava viver ali mais alguns anos, até conseguir ser libertada. 
Tinha tudo planejado, mas aconteceu de ficar doente e ir para o hospital. Sabia que estava morrendo. Por sua alta posição, lhe deram um quarto separado, recebia visitas de damas e militares e a todos prometia interceder junto ao chefe. Da esposa deste, recebia todo domingo um embrulhinho e um pacotinho, mas nenhuma visita. Tia Pólia conseguiu até que um "padre" fosse confessá-la e, depois de sua morte, ser enterrada sob uma cruz. Seu túmulo, na vala comum do hospital, ganhou o ornamento feito por um artista internado. Como ninguém sabia o nome da mulher, a inscrição foi feita com o nome errado e teve que ser corrigida depois, por insistência do tal padre. Este conto mostra, portanto, uma figura que, ainda que seja a de uma escrava, encontra brechas no próprio sistema, não apenas para sobreviver, mas também para ajudar os outros. Mais uma mulher mostrada de maneira positiva por Chalámov, como esperança de vida para os detentos, em contraste com a predominância da morte presente nos campos.

O conto que segue imediatamente "Tia Pólia" é "A gravata" (1958). Trata-se aqui da personagem Marússia Kriúkova, "moça coxa que se envenenou com Veronal, juntou e engoliu vários comprimidos brilhantes, miudinhos, amarelinhos e ovalados". ${ }^{3}$ No entanto, errou a dose e não morreu, apenas vomitou e, depois da lavagem do estômago, foi mandada para um campo provisório. Mas como a personagem chegou até aí? Sua história começa em Quioto, como filha de um emigrado. Nos anos trinta decidiu voltar para a Rússia, conseguiu o visto e foi presa em Vladivostok. No interrogatório quebraram sua perna. Quando o osso cicatrizou, foi mandada a Kolimá. Acontece que Marússia sabia bordar muito bem, habilidade que foi logo descoberta pelos chefes: "Nunca lhe pagavam pelos bordados: davam um pedaço de pão, dois torrões de açúcar, cigarros; a propósito, Marússia não aprendeu a fumar. O admirável bordado, cujo valor chegava a algumas centenas de rublos, acabava nas mãos da chefia". ${ }^{4}$ De todo modo, essa habilidade a protegeu dos trabalhos gerais e ela pôde exercer sua profissão.

${ }^{3}$ Ibidem, p. 165-166,

${ }^{4}$ Ibidem, p. 166. 
Ainda assim, era uma escrava. O narrador a conhece quando ela é internada em seu hospital. Em agradecimento ao tratamento recebido, ela borda uma gravata para ele e uma para o cirurgião. Mas não tem autonomia para dar presentes: o chefe termina por lhe roubar as gravatas. Indignada, Marússia conta essa história ao enfermeiro e, em uma sessão de cinema no campo, onde se encontravam prisioneiros e livres, mostra ao narrador a gravata que seria dele no pescoço do chefe. Escrava. Ainda assim tentando encontrar espaços de resistência.

Nesse contexto, é interessante lembrar da personagem-título do conto "Lida" (1965), presente em A margem esquerda, segundo volume do ciclo. Lida entra na vida do narrador do conto quando este já tinha saído dos trabalhos gerais, do trabalho nas minas, que eram mais que terríveis, fatais. Os últimos anos de pena do narrador foram cumpridos em trabalho interno: como enfermeiro dentro de um hospital. Chalámov conseguira, pela intervenção de um médico seu amigo, fazer um curso de enfermagem para detentos, que salvara sua vida. É nesse período de sua história que se localiza o conto.

Pois bem, Lida entra na vida do narrador quando este era o responsável pela sala de triagem de um grande hospital. Ainda que detento, cabia a ele a decisão sobre quem internar ou não: cargo de grande responsabilidade, já que o hospital era o principal caminho de salvação para prisioneiros extenuados pelas minas. O conto trata do período do final da pena do narrador, que sabia que a libertação não seria uma salvação, ou, melhor, sabia que não seria verdadeiramente libertado, pois possuía, em sua ficha de registro, a fatal letra "T" de trotskista. Esse estigma, pois essa letra não era menos que isso, condenava à morte seus portadores, não permitindo que fizessem outro tipo de trabalho que não os braçais, e não permitiria que o narrador saísse de Kolimá após o fim da pena. Krist, o narrador do conto, ao buscar uma solução urgente, se lembrou de Lida, que conhecera dois anos antes em circunstâncias especiais.

A história dessa moça dá outra mostra da vulnerabilidade das mulheres nos campos, pois se encontravam em condição ainda pior do que os homens: talvez mais escravas que eles, se 
isso fosse possível. Lida, uma presa comum, chegara ao hospital pedindo a internação para fugir do assédio do chefe do campo, de quem era secretária. Para deixar o caminho livre, ele já mandara o marido "de campo" da prisioneira para uma lavra punitiva e não deixava Lida em paz. Krist aceitou-a no mesmo instante, para ajudá-la. O tempo passou e ela acabou permanecendo no hospital, fazendo alguns trabalhos, indo parar na seção de registros, que era onde se encontrava no final da pena de Krist. Este pediu para que ela, ao registrar seu passaporte de saída, "errasse" e se esquecesse da letra " $\mathrm{T}$ ". Ao que ela acedeu prontamente.

Na verdade, há uma outra versão do fim do estigma de trotskista nos registros de Chalámov, narrada por ele próprio em outro conto, que não menciona Lida nem essa troca de favores. Nesta outra versão, o " $\mathrm{T}$ " teria caído quando ele recebe nova pena e, ainda que fosse uma pena de dez anos, acaba lhe salvando a vida, por tirá-lo dos trabalhos gerais. De todo modo, essa história de Lida abre a perspectiva sobre a compreensão do autor a respeito da precária situação da mulher. Ainda que seja uma ficcionalização de aspectos do campo, o conto "Lida" mostra um narrador que se coloca ao lado da mulher e não ao lado do chefete que a assediava. Também mostra uma mulher que luta para se livrar do assédio: vítima, mas tentando elaborar estratégias para sobreviver, o que faz lutando por sua internação. Por outro lado, ela consegue uma posição que, por sua vez, lhe permite ajudar os outros.

No conto "O procurador verde" (1959), Chalámov trata do tema da fuga, ou, na gíria do campo, da "libertação pelo procurador verde". O conto é escrito quase na forma de um ensaio, onde o narrador discorre sobre a necessidade, a vontade, a possibilidade das fugas, sua alta frequência, bem como sobre alguns casos pontuais. Todos fracassados. Mas, no meio disso tudo, relata o caso de um prisioneiro que "quase" conseguiu, à custa de muito sangue frio, cálculo, ousadia. Chegou a ficar dois anos em liberdade, até ser encontrado e pego. E foi pego justamente através de sua mulher. Esse episódio é pertinente para nossa discussão, pois o conto descreve as agruras pelas 
quais passavam as esposas de homens feitos prisioneiros pelo Estado, bem como a força e a coragem que tinham para passar por cima da burocracia, do assédio, de toda a violência, para conseguir um simples encontro com seus maridos. A mulher de Krivochei, o fugitivo em questão, entra no rol das mulheres corajosas, que se sacrificam por seus maridos e os seguem para a prisão. Tradição iniciada talvez com as esposas dos dezembristas, retomada por Dostoiévski em obras como Recordações da casa dos mortos e Crime e Castigo, e que ganha sua versão no contexto do Gulag quase cem anos depois, no terceiro volume de Contos de Kolimá, $O$ artista da pá.

Ainda antes do engenheiro empreender sua fuga, a mulher vai até ele: "Alguns meses se passaram, e a mulher de Pável Mikháilovitch veio de Khárkov para vê-lo. Ela não viera visitá-lo. Não, ela viera para seguir o marido, repetindo a façanha das esposas dos dezembristas". ${ }^{5}$

E, a partir dessa decisão de seguir o marido, as mulheres passavam por toda sorte de martírio:

As esposas que iam atrás dos maridos condenavam a si mesmas ao frio, às constantes torturas das peregrinações atrás dos maridos, que de quando em quando eram transferidos para algum outro lugar, e as esposas precisavam abandonar o lugar de trabalho, achado com dificuldade, e ir em direção a regiões perigosas para as mulheres, onde elas podiam ser submetidas à violência, a roubos, ao escárnio ${ }^{6} .$.

E era só o começo:

Mas, mesmo sem viajar, cada uma dessas mártires estava destinada a passar por galanteios grosseiros e importunações da chefia, começando dos postos mais altos e terminando em um soldado de escolta qualquer, que já tomara gosto pela vida em Kolimá. Receber propostas de fazer companhia a um solteirão bêbado era o fado de todas as mulheres, sem exceção, e se, para uma presa, simplesmente davam ordens - "Tire a roupa e deite-se" -, sem qualquer Púchkin ou Shakespeare, contaminando-a com sífilis, com a esposa de um zek a abordagem era ainda mais atrevida. Pois, após

${ }^{5}$ CHALÁMOV, 2016b, p. 278.

${ }^{6}$ Ibidem, p. 279. 
o estupro de uma presa, era sempre possível deparar-se com uma denúncia feita por um amigo ou adversário, um subalterno ou um chefe, mas o "amor" com a esposa de um zek, como pessoa juridicamente independente, não podia ser enquadrado em nenhum artigo. ${ }^{7}$

Se o zek (acrônimo de zakliutchióni, que significa detento) encontrava-se no degrau mais baixo da escala humana no campo, podemos ter uma ideia então de onde se encontrava a esposa do zek. E todo esse sacrifício era em vão, pois a mulher dificilmente conseguia um encontro com o marido. Dificilmente conseguia encontrar trabalho no mesmo povoado em que ele estava preso. Se conseguia tal façanha, o marido logo era transferido para longe. Ela também não conseguia entregar nenhuma comida para ele. O máximo que alcançava era uma promessa de algum chefete que, em troca de entregar o pão ao marido, exigia da mulher o próprio corpo. Pior ainda se essa fosse a esposa de algum "inimigo do povo". Aí, então, qualquer insulto era "um mérito, uma façanha, e de qualquer forma era considerado positivo do ponto de vista político". ${ }^{8}$

Acontecia de algumas se alistarem para um trabalho de três anos: "Fortes de espírito - e precisavam ter mais força que seus maridos detentos -, elas aguardavam o prazo de seus contratos e iam embora, sem mesmo terem visto os maridos". 9 Muitas vezes perdiam as esperanças e, temendo perseguições no "continente", terminavam por se casar novamente no norte mesmo, esquecendo seus maridos e a si próprias.

Foi esse longo caminho o percorrido pela esposa do engenheiro, que conseguira encontrar um emprego e um lugar para morar em Magadan, Quando o marido fugiu, ela ficou presa no norte: não permitiram seu retorno. O que era extremamente penoso. "Eram-lhe torturantes aquela taciturnidade branca da natureza, aquele muro de cerrada indiferença humana, a completa falta de informação e a inquietação, a inquietação pelo destino do marido - ele podia simplesmente ter morrido

\footnotetext{
7 Idem.

8 Ibidem, p. 280.

${ }^{9}$ Ibidem, p. 281.
} 
de fome no caminho" ${ }^{10}$ Completamente sozinha, ela queria e precisava conversar com alguém, mas com quem? Sentia em todos um espião. Estava certa, todos os seus conhecidos foram convocados, em algum momento, a delatar algo sobre Angelina Grigórievna. De todo modo, no segundo ano de sua permanência no norte, ela começou a receber certa quantidade de dinheiro por mês. E foi justamente essa ajuda, ainda que o marido tomasse todo o cuidado para lhe mandar, que o delatou. As autoridades terminaram por descobrir o paradeiro do engenheiro a partir de seus depósitos. Assim que ele foi capturado, a esposa foi liberada para sair do norte e, esgotada, foi o que fez. Ele ficou preso ainda alguns anos e, quando libertado, arranjou outra mulher. Essa passagem também é interessante para o tema que estamos tratando aqui, pois mostra uma prática do campo, que só o campo poderia engendrar. 0 engenheiro fora arrumar uma mulher na feira de noivas do sovkhoz Elguen.

Próximo ao sovkhoz Elguen, um sovkhoz feminino, há um posto de gasolina, na beira do povoado, "na natureza". Ao lado, colados aos barris de gasolina, há arbustos de salgueiro e amieiro. Ali se reúnem todas as noites as mulheres libertas de Elguen. Também vão para lá, de carro, os "noivos" - ex-presos, que procuravam uma companheira para a vida. Os pedidos de casamento são rápidos, como tudo na terra de Kolimá (exceto a sentença no campo), e os carros retornam com os recém-casados. Tal familiarização, em caso de necessidade, é realizada nos arbustos: os arbustos são espessos o suficiente, altos o suficiente. ${ }^{11}$

Chalámov passa bastante tempo descrevendo a situação da mulher nesses casos, o que foi reproduzido aqui em grande parte. Nota-se, em seu texto, uma simpatia pela condição feminina, uma compreensão a respeito da precariedade de sua situação e, por outro lado, uma admiração por sua força e até mesmo, por que não, por sua capacidade de se sacrificar.

Para falar do tema do feminino na obra de Chalámov, dois textos ainda chamam bastante a atenção. Um deles é "A mulher

\footnotetext{
10 Ibidem, p. 286.

${ }^{11}$ Ibidem, p. 290.
} 
no mundo do crime" (1959), que se encontra no quarto volume de Contos de Kolimá, Ensaios sobre o mundo do crime. Este volume é um tanto diferente do restante do ciclo. Ele traz o que o próprio nome indica: ensaios e não contos. $O$ tema do mundo do crime foi extremamente importante para Chalámov e, de certa forma, moldou sua visão de mundo pós-campo e sobre o campo. Para o escritor, o bandido da ordem, ou seja, o bandido que pertencia àquela espécie de máfia que se formara nos campos stalinistas, era o grande responsável pelo clima irrespirável e deletério que reinava. Ou seja, mais do que as autoridades, a escolta, os chefetes, quem realmente instaurou a violência desmedida $\mathrm{e}$ gratuita nos campos foram os bandidos. Chalámov dedicou um volume inteiro de seus Contos de Kolimá ao tema.

Segundo o conto-ensaio, as mulheres no mundo do crime se dividiam em dois grupos: as ladras, que tinham a função de roubar, como os homens, e as prostitutas, que faziam companhia aos blatares (gíria do campo para os bandidos que pertenciam à ordem). O primeiro grupo era menor que o segundo e as ladras gozavam de certa deferência entre os ladrões. Também planejavam roubos, executavam ações, mas jamais participavam dos chamados "tribunais de honra", prerrogativa dos homens. Ainda que em condições desiguais em relação aos homens, gozavam, portanto, de certo respeito.

Já as prostitutas eram as amigas dos bandidos e lhes arranjavam meios de viver. Se houvesse necessidade, auxiliavam nos roubos, praticando pequenas ações, tais como a vigília, o repasse do produto do roubo e outros. Mas estavam em último lugar na escala humana. $O$ narrador comenta:

O desprezo pelas mulheres é ensinado desde os primeiros anos aos herdeiros dos urkas. Alternam-se aulas teóricas e práticas com exemplos concretos dos mais velhos. A mulher - um ser inferior - foi criada somente para saciar as bestiais paixões dos bandidos e, por ocasião de suas farras, ser alvo de grosserias e objeto de espancamento em público. Um objeto vivo de que o blatar temporariamente se serve. ${ }^{12}$

12 Ibidem, p. 63. 
Esse parágrafo contundente resume o lugar e o tratamento da maioria das mulheres no mundo do crime. Uma diferença de grau, talvez, de intensidade, se comparada à situação no restante dos campos, onde a mulher também não passava de um objeto. Nesse contexto, os estupros coletivos não eram raros, fosse no mundo do crime ou não.

A mulher prostituta estava longe de ser dona de seu destino, ou de seu corpo:

E se ontem, antes do aparecimento desse novo cabeça, a prostituta dormia com outro ladrão, de quem era considerada uma propriedade, e que tinha o direito de oferecê-la aos companheiros, com o surgimento de outro cabeça dá-se a transferência de todos esses direitos ao novo patrão. Se amanhã ou depois este for detido, ela volta a pertencer a seu antigo companheiro. E se aquele já estiver detido quando isso ocorrer, então apontam a ela quem será seu novo proprietário - senhor de sua vida e morte, de seu destino, seu dinheiro, sua conduta e seu corpo. ${ }^{13}$

E eram obrigadas a ir com quem fosse: mero objeto dos bandidos. Nenhuma equidade era possível em relação às mulheres. Segundo o narrador, apenas uma mulher escapava a esse tratamento: a mãe do bandido. "O culto à mãe unido ao hostil desprezo pelas mulheres em geral - eis a fórmula ética da bandidagem para a questão feminina, expressa com o peculiar sentimentalismo da cadeia". ${ }^{14}$ Cercado por um mundo impiedoso, o bandido sabe que só a mãe ficará com ele até o final.

Mas o narrador aponta a falsidade de tal sentimento, que chama de "fingimento e falsidade teatral". Pois a mãe, enaltecida pelo bandido, colocada em um pedestal, nunca recebe uma ajuda desse filho que ganha milhares de rublos roubados. Para o narrador, "o culto à mãe é uma espécie de cortina de fumaça que esconde o indecoroso mundo do crime". Pois, "um culto à mãe que não se estende à esposa, nem às mulheres em geral, não passa de mentira e falsidade". As obrigações da paternidade, por exemplo, passam bem ao largo da imagina-

\footnotetext{
${ }^{13}$ Ibidem, p. 63.

14 Ibidem, p. 73.
} 
ção do blatar. Este não tem nenhuma crise de consciência em considerar para a própria filha um futuro como prostituta ou até mesmo como companheira de um ladrão importante. No contexto da relevância do mundo do crime na configuração assustadora do lager, "a atitude em relação às mulheres é o papel de tornassol de toda a ética". ${ }^{15}$ Nessas observações do narrador, notamos um homem indignado com a situação da mulher e, ao mesmo tempo, a importância que a questão feminina tem para ele, pois é a expressão de toda a ética do mundo do crime e, por consequência, do mundo do campo.

Para terminar, o último texto a ser tratado neste trabalho é um longo conto, presente em $A$ ressurreição do lariço. Trata-se de "A medalha de ouro" (1966). Diferente da maioria dos contos presentes nos seis ciclos, mas acompanhando os outros mostrados neste trabalho, a protagonista é uma mulher. Além disso, não é uma vítima e sim uma lutadora, vista pelo narrador como uma heroína. Seu nome: Natália Seguêievna Klímova, revolucionária do Partido Socialista Revolucionário. Para escrever essa história, Chalámov teve contato com sua filha mais velha, além de ter feito uma detalhada pesquisa. Se o escritor já nutria bastante simpatia por esse grupo, das páginas do conto exala profunda admiração pela moça. Como vamos ver, pelas moças, mãe e filha.

Condenada à morte por um atentado terrorista, Natália Klímova, ainda bem jovem, tem sua pena comutada para trabalhos forçados pela intervenção do pai, que, em um requerimento ao presidente do tribunal, fala em um tom estranho, quase que de pai para pai, desconsiderando sua filha como pessoa, como ser pensante, como alguém capaz de fazer escolhas por ela mesma. Para esse pai, tratava-se apenas de uma deslumbrada, que pulara do tolstoísmo para o terrorismo de repente, que não entendia nada de política e com certeza tinha sido instruída por outras pessoas. Por isso, não merecia a condenação. A morte do pai tornara o requerimento praticamente irrefutável e aquele consegue seu intento.

15 Ibidem, p. 74. 
Chalámov não esconde a admiração pela autora da Carta perante a execução, publicada em 1908. Klímova escrevera esse texto no cárcere: comunhão com a natureza, frescor de sentimentos, sinceridade, liberdade. Nem fanatismo, nem didatismo. ${ }^{16} \mathrm{~A}$ mulher aparece nesse conto não como vítima, mas como a própria força de vida: Klímova era radiante,

aceitava de bom grado toda a felicidade da existência, porque aceitava a vida em sua completude, com alegrias e mágoas, ligadas organicamente, inseparáveis. Isso não era uma concepção filosófica, mas um sentimento espontâneo de uma natureza rica e forte. Ela via tanto no heroísmo como no sacrifício a maior, a mais desejada felicidade da existência. ${ }^{17}$

Chalámov pesquisou a vida de Klímova ao lado de sua filha, que trazia o mesmo nome da mãe. Nessa outra Natália, Chalámov descobre a mesma força vital da mãe, ainda que esta se expressasse de outra maneira, pois tratava-se de outro mundo, outra época, outras questões e tragédias. Ao voltar para a Rússia, para a terra de sua mãe, essa mulher fora parar nos campos de trabalho, onde passa dez anos. Eis aí sua façanha: "conservar a fé no ser humano por meio de sua experiência pessoal, de sua vida, não era proeza menor que a causa de sua mãe". ${ }^{18} \mathrm{E}$, ainda que fosse filha de quem era, decide deixar o passado para trás e viver, seguir o seu próprio destino. Se desfaz de uma medalha de ouro, última lembrança de sua mãe, pois o mais importante era sobreviver. Eis sua força.

$O$ recorte feito para o presente trabalho buscou, portanto, apresentar contos e trechos onde o olhar de Chalámov para a mulher é perceptível. Nesse contexto, podemos observar um escritor sensível para a questão feminina: tendo conhecido o pior dos campos stalinistas, Chalámov deixa claro em sua prosa a ideia de que o quinhão mais difícil sempre coube às mulheres. Ainda que descreva, indignado, vítimas, também aponta mulheres que conquistaram, cada uma a seu modo, um mínimo de autonomia. Que conseguiram, de certa forma, lutar por sua sobrevivência.

\footnotetext{
16 Ibidem, p. 184.

17 Ibidem, p. 191

18 Ibidem, p. 211.
} 
Na obra de Chalámov, os homens aparecem como vítimas, carrascos, cruéis, sobreviventes. Positivos e negativos. As mulheres, salvo engano, são retratadas como uma contraposição ao terror. Como vimos ao longo do artigo, representam a esperança, uma luz no fim do túnel, ou no fim do dia. Mas a humanidade que a mulher traz em sua obra joga uma luz que torna a violência ainda mais terrível. Não só pelo contraste que sua coragem, compreensão, força e generosidade fazem aos atos desumanos dos homens, como também por sua vulnerabilidade. É como se a presença da mulher nos contos agudizasse $o$ horror; um respiro para aprofundar ainda mais o absurdo.

Outro dado interessante na relação do autor com essas personagens é que, mesmo quando as mulheres são autoras de atos de brutalidade - como algumas mulheres do mundo do crime, por exemplo -, há sempre o contexto de sua posição subalterna em relação aos homens que, se não justifica tais atos, de certa forma, os torna mais humanos. Há bastante diferença na forma com que os homens e as mulheres do mundo do crime são retratados: para Chalámov, os bandidos não eram gente. E mesmo o tratamento que dispensavam às mulheres é uma prova dessa afirmação. Quanto às mulheres do crime, enquanto sua força é admirada pelo autor, sua posição de objeto do homem, sua fragilidade, são denunciadas com indignação.

A descrição da mulher nesse mundo é contundente, pelo horror que encerra, mas também por outro motivo: a maneira como a mulher é tratada revela a ética de todo um grupo. Ao descrever a maneira com que o bandido se serve da mulher, Chalámov mostra toda a violência e absurdo do mundo do crime e seu papel deletério nos campos. Podemos pensar também que a maneira como o autor vê a situação da mulher diz muito sobre sua própria ética, sobre seu olhar para a vida. Em suas personagens femininas se expressa, talvez, o que ele mais abomina: a desumanização do homem; e o que mais admira, a força de vida.

O conto "A medalha de ouro" mostra duas mulheres fortes, que acreditam na vida e não se deixam abater. Nem mesmo pelo sofrimento vivido nos campos, máquinas devoradoras de 
gente. Talvez seja o conto onde a humanidade e a crença nela apareçam de maneira mais resplandecente. E mostram-se através de personagens femininas, que tiram sua força da natureza, da comunicação direta com os animais, da fé na vida. Fé que o próprio Chalámov, apesar de seus sofrimentos e ceticismo, também nunca chegou a perder.

\section{Referências Bibliográficas}

CHALÁMOV, Varlam. Contos de Kolimá. Tradução de Denise Sales e Elena Vasilevich. São Paulo: Editora 34, 2015.

A margem esquerda (Contos de Kolimá 2). Tradução de Cecília Rosas. São Paulo: Editora 34, 2016a.

O artista da pá (Contos de Kolimá 3). Tradução de Lucas Simone. São Paulo: Editora 34, 2016b.

Ensaios sobre o mundo do crime (Contos de Kolimá 4). Tradução de Francisco de Araújo. São Paulo: Editora 34, 2016c.

A ressurreição do Lariço (Contos de Kolimá 5). Tradução de Daniela Mountian e Moissei Mountian. São Paulo: Editora 34, 2016d.

DOSTOIÉVSKI, Fiódor. Recordações da casa dos mortos. São Paulo: Nova Alexandria. 2006. 